\title{
Percepção Conceitual Sobre Sustentabilidade: um Levantamento com Gestores de um Shopping
}

\author{
Aritana Paola Santos Carvalho Novais ${ }^{1}$, Adriano Victor Lopes da Silva ${ }^{2}$, \\ Erika Maria Jamir de Oliveira ${ }^{3}$
}

\begin{abstract}
Resumo: Este estudo teve como objetivo conhecer a percepção conceitual dos gestores de empresas situadas em um Shopping de Juazeiro-BA sobre a sustentabilidade. A pesquisa possui caráter exploratório e foi realizada por meio de um estudo de caso, a amostra foi a aleatória simples, os 29 proprietários e gerentes participantes foram determinados no software R 3.3.0, os dados foram coletados através de entrevistas, instrumentalizada por um questionário estruturado, em seguida os dados foram tratados através da análise de conteúdo temática. Aplicou-se o teste do qui-quadrado no software BioEstat 5.3 para verificar se o conhecimento sobre sustentabilidade independe do grau de escolaridade. Os resultados encontrados revelam que a maioria dos entrevistados associa a sustentabilidade como atitude direcionada ao meio ambiente. As empresas desenvolvem atividades voltadas a sustentabilidade e que os gestores conhecem o conceito de sustentabilidade.
\end{abstract}

Palavras-Chave: sustentabilidade, competitividade, social, econômico, meio ambiente.

\section{Conceptual perception on Sustainability: A survey with managers of a mall}

\begin{abstract}
This study was aimed at knowing the conceptual perception of the managers of companies located in a shopping-BA on sustainability. Research has an exploratory character and was carried out through a case study, the sample It was the simple random, The 29 owners and managers participants were certain in software R 3.3.0, the data were collected through interviews, instrumentalization for a questionnaire structured, then the data were treated through the analysis of thematic content. The chi-squared test was applied in the software BioEstat 5.3 to check If knowledge about sustainability is independent of the degree of education. The results found reshow that most of the interview associates sustainability as an attitude towards the environment. The companies develop activities focused on sustainability and that the managers you know the concept of sustainability.
\end{abstract}

Key-words: sustainability; competitiveness; social; economic; environmental

\footnotetext{
${ }^{1}$ Graduada em Administração de Empresas pela Faculdade São Francisco de Juazeiro/BA - FASJ, e pós-graduada em Gestão de Pessoas pela Faculdade de Ciências Aplicadas e Sociais de Petrolina - FACAPE.

Contato: aritana.paola@gmail.com;

${ }^{2}$ Universidade Federal do Vale do São Francisco. Contato: adriano.victor@univasf.edu.br;

${ }^{3}$ Graduação em Administração pela Faculdade Maurício de Nassau - Recife. MBA em Gestão Empresarial pela Faculdade Maurício de Nassau - Recife e Especialização em Gestão Pública pela Universidade Federal do Vale do São Francisco Petrolina. Mestra em Ciências da Saúde e Biológicas (INTERDISCIPLINAR) da Universidade Federal do Vale do São Francisco - Petrolina. Professora no curso de Administração da Universidade Federal do Vale do São Francisco. Tutora à distância da SEaD no curso de Especialização em Gestão Pública Municipal da Universidade Federal do Vale do São Francisco. Contao: erikamariajamirdeoliveira@gmail.com.
} 


\section{Introdução}

As organizações que almejam ser competitivas, estão sempre em constante renovação para oferecer ao mercado de consumo produtos que são, possivelmente, frutos do seu bom desempenho social, ambiental e econômico. Por isso, essas organizações estão atentas às tendências e exigências do mercado, uma delas se refere às práticas inovadoras e sustentáveis. Ou seja, essas empresas podem gerar mais valor para a sociedade no longo prazo, por meio da transparência e sustentabilidade.

Assim, destaca-se a relevância deste estudo proposto em analisar as organizações de um shopping, local onde o consumo notadamente é o ápice comportamental das pessoas, causando-se um índice elevado de produção de lixo, um alto consumo de energia e água, englobando os fatores ambientais e possivelmente proporcionando uma análise crítica nas perspectivas sociais e econômicas. Considerando-se que uma boa prática sustentável em essência não é apenas boa para alguns, é boa para muitos, trata-se da sobrevivência e do futuro para novas gerações.

Para pressionar essa mudança, a Organização das Nações Unidas (ONU) elaborou metas para os países membros. São objetivos para que eles alcancem o desenvolvimento sustentável até 2030, com a finalidade de buscar concretizar os direitos humanos de todos e alcançar a igualdade de gênero. Eles equilibram as três dimensões do desenvolvimento sustentável: a econômica, o social e a ambiental. Cada objetivo e metas são necessários para a viabilidade de uma sociedade sustentável.

Assim, pode-se perceber através de estudos realizados como por exemplo: Reis (2015), Froehlich (2014), Medici (2015), que as organizações brasileiras estão cada vez mais evoluindo com as práticas sustentáveis e capacitando seus empregados para trabalharem de forma sustentável. Mas, muitas delas ainda não se encontram conscientizadas de suas obrigações com o meio ambiente. Pois são atividades que demandam um poder aquisitivo maior ou talvez pela falta de compreensão de seus empregados do que significa sustentabilidade, assim dificultando o discernimento das atitudes que devem ser tomadas no dia a dia do seu trabalho (BENCH MAIS 3, 2015, p. 66). 
O assunto sustentabilidade é intensamente discutido. Os estudos de Froehlich (2014), Silva; Reis; Amâncio (2014), mostram o quanto a sustentabilidade já evoluiu, como um fator de grande importância na sociedade e a maneira como as pessoas vem praticando ela dentro das organizações. Trazendo retorno de forma econômica, social e para o meio ambiente.

Sendo assim, o problema que norteou este artigo pode ser resumido na seguinte questão: como se encontra a percepção conceitual dos gestores de um conjunto de empresas situadas em um shopping sobre sustentabilidade?

O objetivo deste estudo foi identificar a percepção de como se encontra o conhecimento dos gestores de empresas de pequeno e médio porte situadas no Shopping de Juazeiro-BA sobre a sustentabilidade, bem como saber se os gestores acreditam que exista alguma relação entre sustentabilidade e competitividade.

\section{Surgimento da sustentabilidade: principais fatos históricos}

O tema sustentabilidade começou a ser discutido no encontro do Clube de Roma, grupo formado por pesquisadores e empresários. Na ocasião, pontuou-se a preocupação com o ritmo do crescimento industrial e, por conseguinte, a exploração dos recursos naturais, os níveis de poluição e a degradação ambiental. Foram apresentadas ações e atitudes, individuais e coletivas, necessárias para encontrar o equilíbrio entre o desenvolvimento econômico, social e a preservação do meio ambiente (REIS, 2015, p. 112).

Neste encontro foi desenvolvido um artigo intitulado "Os Limites do Crescimento" de autoria do Clube de Roma, evidenciando a preservação ambiental, que segundo Froehlich (2014, p. 180) foram abordados temas relevantes para o reequilíbrio ambiental.

Em 1987, foi publicado o Relatório Brundtland, um documento intitulado Nosso Futuro Comum. Neste documento, o desenvolvimento sustentável é concebido como:

"O desenvolvimento que satisfaz as necessidades presentes, sem comprometer a capacidade das gerações futuras de suprir suas próprias necessidades". O relatório alertou sobre a falta de conciliação entre o desenvolvimento sustentável e os padrões de produção (SILVIA; REIS; AMÂNCIO, 2014, p. 91). 
Considera-se então, que a preocupação com o meio ambiente surge após um desequilíbrio causado no planeta pelo avanço da industrialização. A maior preocupação era impedir o consumo acelerado, para evitar a escassez de produtos não renováveis. A responsabilidade social começou a ser mencionada nas organizações na década de 1950, percebendo a necessidade das empresas de exercer ações favoráveis para a sociedade em geral (SILVIA; REIS; AMÂNCIO, 2014, p. 92).

Em 1972, ocorreu a primeira manifestação mundial sobre o meio ambiente.

Surgiu a Conferência das Nações Unidas sobre o Meio Ambiente Humano em Estocolmo, Suécia, onde foi criado o Programa das Nações Unidas sobre o Meio Ambiente (PNUMA) (DIAS, 2011, p. 40).

Com o passar dos anos e a necessidade cada vez maior de trabalhar os aspectos ambientais, segundo Medici (2015, p. 29), em 1992 aconteceu no Rio de Janeiro, com a participação de 170 estados, o mais importante fórum mundial já realizado, a Cúpula da Terra, onde foi elaborada a Agenda 21, um documento que propõe um novo padrão de desenvolvimento conciliando -se proteção ambiental, justiça social e eficiência econômica. A ONU (Organização da Nações Unidas) elaborou metas que integram os três padrões de desenvolvimento elaborados na Agenda 21. Pode-se observar no Quadro 1.

Quadro 1 - Metas da ONU para 2030.

- Acabar com a pobreza em todas as suas formas, em todos os lugares;

- Acabar com a fome, alcançar a segurança alimentar e melhoria da nutrição e promover a agricultura sustentável;

- Assegurar uma vida saudável e promover o bem-estar para todos, em todas as idades;

- Assegurar a educação inclusiva e equitativa de qualidade, e promover oportunidades de aprendizagem ao longo da vida para todos;

- Alcançar a igualdade de gênero e empoderar todas as mulheres e meninas;

- Assegurar a disponibilidade e gestão sustentável da água e saneamento para todos;

- Assegurar o acesso confiável, sustentável, moderno, e a preço acessível à energia, para todos; 


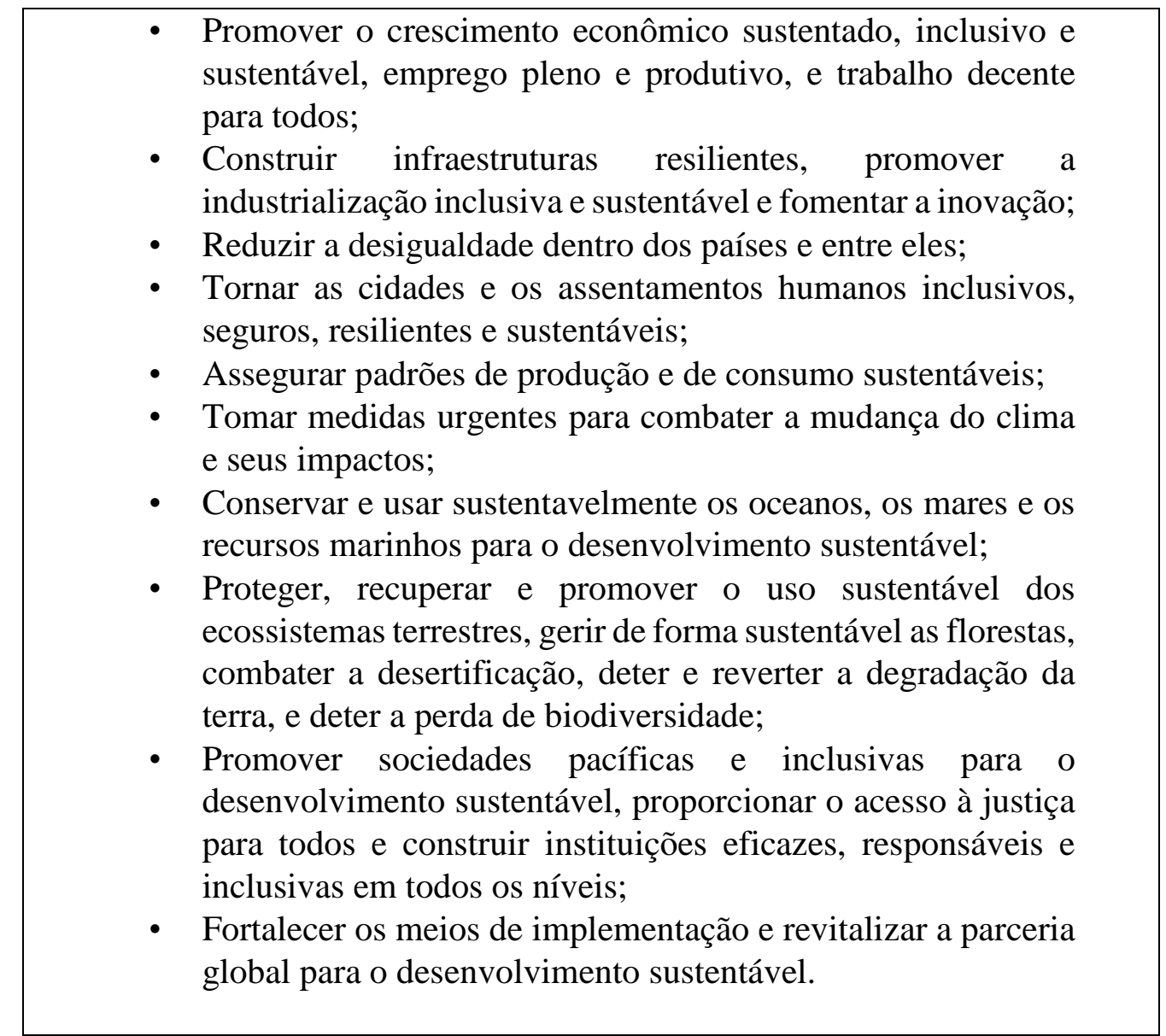

Fonte: (ONU, 2018).

Relata-se nesse estudo, os fatos históricos mais mencionados nos livros de sustentabilidade. Eles mostram a importância de manter uma frequência de atitudes, voltadas a melhoria do nosso planeta, através do esforço de países que, unidos, desenvolvem estratégias e programas para buscar o equilíbrio da sustentabilidade ambiental, social e econômica.

\section{A sustentabilidade e os seus três pilares: ambiental, econômico e social}

Segundo Medici (2015, p. 26), no contexto organizacional a palavra sustentabilidade vem do termo latim sustentare, com três significados: sustentar, defender e conservar. Esses três conceitos são essenciais para evitar o consumo desnecessário dos recursos naturais. 
Com o passar dos anos, percebeu-se que a sustentabilidade precisava estar integrada em três pilares para realmente evoluir de forma correta, o social, econômico e ambiental. Pode-se ser observado no Quadro 2.

Quadro 2- Discriminação dos três Pilares da Sustentabilidade.

\begin{tabular}{|l|l|l|}
\hline Sustentabilidade Social & Sustentabilidade Econômica & Sustentabilidade Ambiental \\
\hline $\begin{array}{l}\text { Contempla todo o capital } \\
\text { humano, incluindo, além de } \\
\text { funcionários, também } \\
\text { fornecedores, clientes e a } \\
\text { sociedade. }\end{array}$ & $\begin{array}{l}\text { A empresa precisa ser capaz } \\
\text { de se manter economicamente } \\
\text { no mercado competitivo. }\end{array}$ & $\begin{array}{l}\text { Se refere a todas as aços que } \\
\text { possuam algum impacto direto } \\
\text { ou indireto ao meio ambiente. }\end{array}$ \\
\hline
\end{tabular}

Fonte: (DIAS, 2011).

Outra forma de se entender o conceito dos três pilares da sustentabilidade é através da expressão Triple Bottom Line que surgiu na década de 1990, também conhecida como os três Ps (People, Planet and Profit, ou, em português, Pessoas, Planeta e Lucro). Durante muito tempo as empresas só se preocupavam com os resultados financeiros. Nos últimos anos os resultados de uma empresa são medidos em termos econômicos, ambientais e sociais. São apresentados nos relatórios de sustentabilidade corporativa através de dados e aferições voluntárias (DIAS, 2011, p. 46). A Figura 1, representa o equilíbrio permanente da sustentabilidade nas organizações.

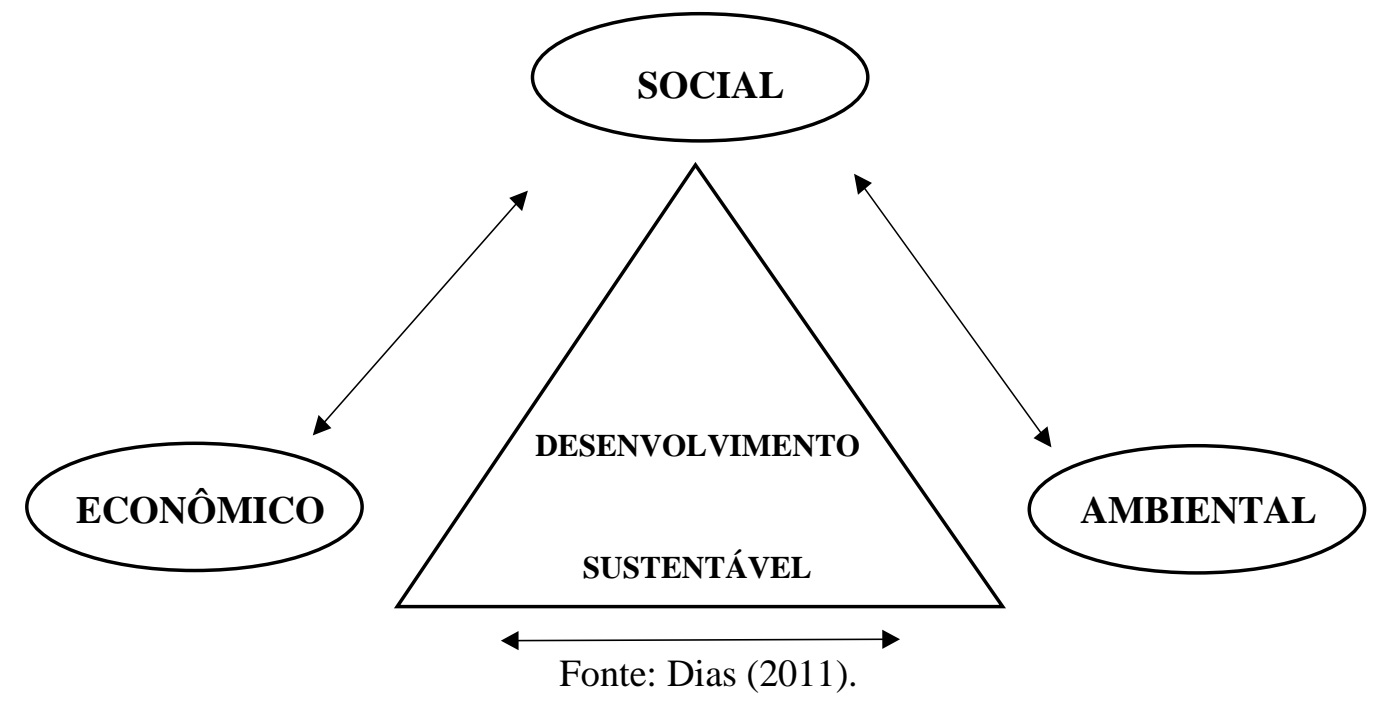

Figura 1 - Triple Bottom Line ou o Tripé da Sustentabilidade. 
Através de comparação entre estudos já realizados como os de Silva; Reis; Amâncio (2014), e de Froehlich (2014) entende-se que, embora a sustentabilidade seja algo bastante mencionado, ainda precisa ser estudada com maior profundidade pelas pessoas para sua melhor compreensão. Sendo necessário conciliar cada vez mais o crescimento econômico com a preservação do meio ambiente.

\section{Possíveis relações entre competitividade e sustentabilidade}

A gestão ambiental vem adquirindo uma posição de destaque na competitividade entre as organizações, em consequência dos benefícios que traz ao processo produtivo como um todo. Atualmente, as empresas que cumprem as exigências normativas ecológicas, conseguem obter melhoria no desempenho ambiental da empresa, com maior possibilidade de inserção no mercado cada vez mais exigente com relação a proteção ambiental, adquirindo melhoria da sua imagem perante aos clientes e comunidade (DIAS, 2011, p. 63).

Nessa mesma linha, Reis (2015, p. 112) afirma que empresas modernas têm incorporado a visão de que ser sustentável é ser competitivo. Há alguns anos atrás, não existiam praticamente diretorias ou gerências de sustentabilidade nas empresas.

Atualmente já houveram mudanças significativas nesse setor, essas áreas de atividade são parte integrante do planejamento estratégico das empresas.

Montaño (2002) e Cabette (2004), citados por Gollo L. B et al. (2013, p. 21), menciona em seu estudo sobre uma análise da sustentabilidade socioambiental, a percepção de que, apesar de toda a necessidade de se implementar a sustentabilidade, não acreditam no seu significado. Porém, Cavalcanti (2003), Bruseke (2003) e Leonardi (2003), também citados por Gollo L. B et al. (2013, p. 21), acham que a sustentabilidade é incompatível com a realidade, mas não impossível de se implementar, tendo a percepção de que a sustentabilidade já está caminhando, porém, não de forma adequada, a suprir uma sociedade que não resiste a falta de recursos.

O ser humano, com a evolução do mercado de consumo, e a comodidade de sempre suprir suas necessidades, está acostumado de forma cômoda ao mercado de consumo ter tudo à disposição. 
Pode-se considerar, que as organizações que não se adaptarem às necessidades ambientais poderão ter dificuldades em se manterem, em um mercado de consumo cada vez mais consciente, buscando empresas cidadãs e que mantém dentro de suas estratégias corporativas ações sustentáveis.

As organizações que não se reinventarem buscando inserir a questão da sustentabilidade em suas ações, poderão ter dificuldades em conquistar novos clientes e, também, em manter os já existentes. As exigências da sociedade estão cada vez maiores, em consumir produtos de empresas notadamente sustentáveis em sua essência. Hoje, não está mais tão simples manter uma imagem de sustentabilidade que não esteja pautada em ações concretas com viés ambiental, seja na produção, venda ou prestação de serviços ao consumidor final.

A questão ambiental tem sido um dos temas mais frequentes nos fóruns mundiais sobre estratégias corporativas e, também, da própria sobrevivência da humanidade, em longo prazo. Isto tem ocorrido com alta frequência, tendo em vista os estudos científicos da deterioração dos recursos naturais que efetivamente já trazem efeitos destrutivos na sociedade como um todo, e em todas as cadeias de produção até o produto final. Muitos desmatamentos, poluição excessiva pelos veículos automotores, o desgaste da camada de ozônio, são apenas alguns exemplos de ações prejudiciais ao meio ambiente, que estão em pauta constante nos encontros organizacionais sobre o assunto Sustentabilidade. No entanto, no que se diz respeito a sustentabilidade social e econômica, percebe-se segundo os estudos analisados, que ainda existe uma certa deficiência no conhecimento das áreas e poucas atitudes voltadas a sua prática.

\section{Estratégia metodológica}

Para o alcance do objetivo proposto, identificar a percepção dos gestores de empresas sobre sustentabilidade, empregou-se a pesquisa exploratória. Conforme Marconi e Lakatos (2010), este estudo é o método utilizado quando o principal objetivo é familiarizar-se com problema, fenômeno ou situação tornando mais claros alguns conceitos.

Aplicou-se a técnica de estudo de caso. Como demostra Bertucci (2012, p. 52), a característica é o aprofundamento de um determinado objeto, visando a melhoria do conhecimento ou a análise detalhada de uma situação. A empresa escolhida foi um shopping 
que se categoriza como o maior shopping da Cidade de Juazeiro-BA. Fator que, proporcionou o tamanho da amostra de 63 lojas a realização da entrevista com 29 participantes.

Foi aplicado o modelo de amostra probabilística, mais especificamente a amostra aleatória simples que, consiste em uma das principais maneiras de extrair uma amostragem de qualquer população, onde os indivíduos possuem a mesma probabilidade de serem escolhidos. $\mathrm{Na}$ sua aplicação, as lojas foram sorteadas de forma aleatória, para serem entrevistados os gestores. Os participantes foram determinados pelo software livre R versão 3.3.0. (BRUNI, 2011). O tamanho da amostra foi estabelecido a partir do cálculo da seguinte equação:

$$
\begin{gathered}
N \cdot \hat{p} \cdot \hat{q}\left(Z_{\alpha / 2}\right)^{2} \\
n=\hat{p} \cdot \hat{q}\left(Z_{\alpha / 2}\right) 2+(N-1) \cdot E_{2}
\end{gathered}
$$

Onde: $\mathrm{n}=$ número de indivíduos na amostra;

$\mathrm{Z} \alpha / 2=$ variável normalmente padronizada associada ao nível de confiança; $\mathrm{p}=$ proporção populacional de indivíduos que pertence a categoria que estamos interessados em estudar; q= Proporção populacional de indivíduos que não pertence à categoria que estamos interessados em estudar $(\mathrm{q}=1-\mathrm{p})$;

e $=$ Margem de erro ou erro máximo de estimativa. Identifica a diferença máxima entre a proporção amostral e a verdadeira proporção populacional (p).

A coleta de dados se deu por meio de entrevistas, instrumentalizada por um questionário estruturado, seguindo um roteiro de questões previamente estabelecidas, trazendo a possibilidade de comparação entre as respostas obtidas, com o objetivo de conhecer a concepção do entrevistado sobre sustentabilidade (BERTUCCI, 2012).

A presente pesquisa possui dados secundários, documento informado pela administração do shopping. Quanto a análise dos dados, o Quadro 3. Demostra as etapas da análise do conteúdo. 
Quadro 3. Etapas da análise do conteúdo.

\section{PRÉ-ANÁLISE}

\begin{tabular}{|l|l|}
\hline Passo 1: Leitura Flutuante & $\begin{array}{l}\text { Foi feita uma leitura flutuante dos dados } \\
\text { coletados, com o objetivo de identificar } \\
\text { padrões nas respostas dos participantes. }\end{array}$ \\
\hline
\end{tabular}

\section{EXPLORAC̃̃O DO MATERIAL}

Passo 2: Codificação do material

Exploração do material com a finalidade de identificar, categorias sobre o tema sustentabilidade, ou seja, elementos comuns entre eles. Sendo que cada elemento só pode existir em uma categoria.

TRATAMENTO DOS RESULTADOS, INFERÊNCIA E INTERPRETAÇ̃̃O

Passo 3.1: Categorização

Fonte: Adaptado de Bardin (2004).
Os elementos foram organizados através de características comuns, sobre um título genérico a todos. Em seguida, analisou-se os dados através de tabelas calculadas de forma estatística.

Os dados foram tabulados no Excel, depois elaborou-se tabelas para apresentar os resultados, porém, por motivos de adequação ao uso da tabela, foram expostas apenas as categorias que se apresentou no mínimo três vezes.

Para verificar se o conhecimento do conceito de sustentabilidade independe do grau de escolaridade dos gestores, utilizou-se o teste do qui-quadrado, que foi aplicado no Software Bioestat 5.3 com o nível de significância de $5 \%(\mathrm{x}=0,05)$, este teste é utilizado para verificar a hipótese de existência de independência ou associação de uma frequência observada em características de um determinado fato (BRUNI, 2011).

\section{Resultados e discussão}

Pode ser observado na Tabela 1, que foram entrevistados consultores, gerentes e proprietários. Destacando-se, os gerentes como maior parte dos participantes. A pesquisa foi realizada com pessoas de diversas idades assim, verificou-se que, a faixa etária de idade, corresponde à média de 32,27 entre os entrevistados. 
Tabela 1. Demonstrativo da distribuição de cargos entre os entrevistados.

\begin{tabular}{c|c}
\hline Função & Quantidade \\
\hline Gerente & $79 \%$ \\
\hline Proprietário & $17 \%$ \\
\hline Consultor & $04 \%$ \\
\hline
\end{tabular}

Fonte: Dados da pesquisa (2017).

Pode-se perceber na Figura 2, o grau de escolaridade das pessoas entrevistadas, 41,37\% possui o ensino médio completo, entretanto, 48,27\% correspondem aos indivíduos com graduação completa e incompleta. Os outros $1,02 \%$ dos entrevistados corresponde aos que possuem, pós-graduação completa e incompleta. Logo, a maioria dos entrevistados possui o ensino superior.

Figura 2. Grau de escolaridade das pessoas entrevistadas.

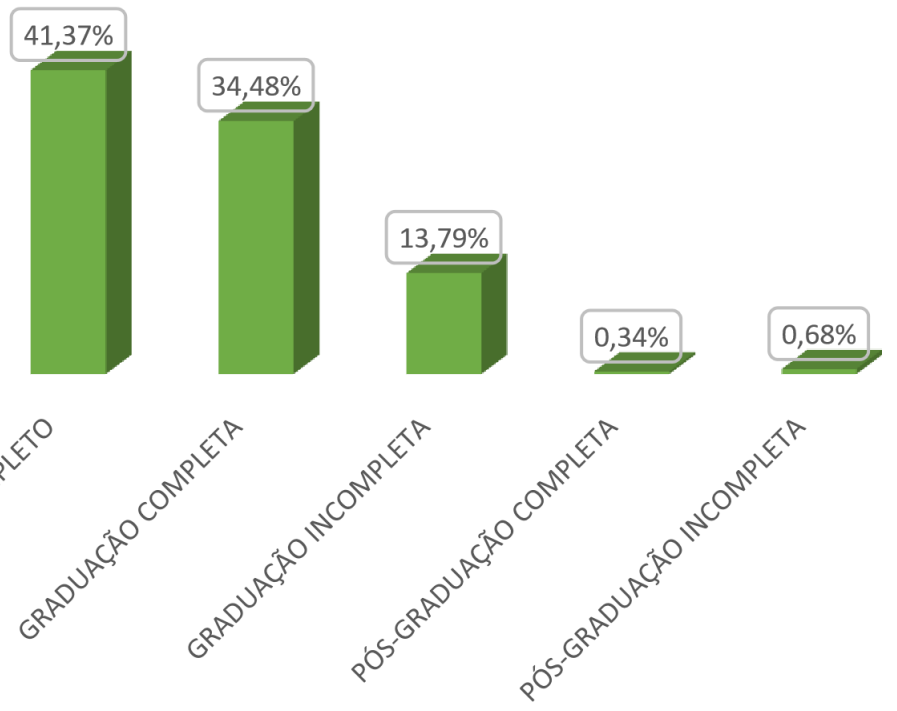

Fonte: Dados da pesquisa (2017).

Pode ser observado no Mapa de árvore as palavras mais frequentes que os participantes da entrevista identificaram como sendo relacionadas a sustentabilidade. Como pode ser visto na Figura 3, as palavras mais mencionadas foram: meio ambiente, preservação e reciclagem. Analisando-se essas palavras, percebe-se que a maioria dos entrevistados ainda associa a sustentabilidade como atitude voltada ao meio ambiente. A pesquisa mostrou poucos indícios 
de palavras citadas voltadas a sustentabilidade social e econômica. Silva et al. (2014), apresentou um estudo semelhante indicando os significados associados a sustentabilidade sendo mais recorrente as palavras: responsabilidade socioambiental, sustentabilidade a investimentos, programas ou ações socioambientais.

Figura 3. Mapa de árvore das palavras mais frequentes relacionadas a sustentabilidade.

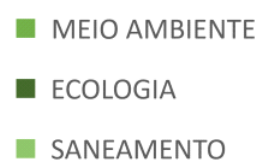

- PRESERVAÇÃo

PESSOAS

RECICLAGEM

- SANEAMENTO

- ECONOMIA
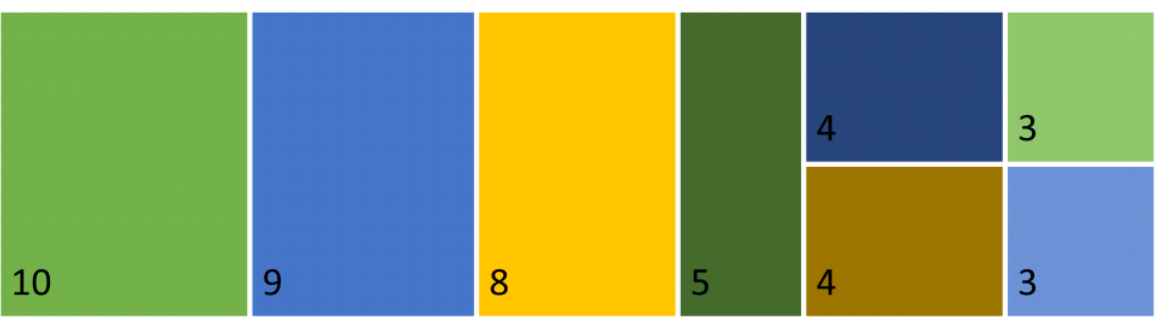

Fonte: Dados da pesquisa (2017).

Diante dos dados analisados na Tabela 2, percebe-se que a maioria das empresas participantes praticam e desenvolvem atividades voltadas a sustentabilidade. De um total de 29 empresas, 75,86\% dos entrevistados praticam a sustentabilidade nas organizações e 24,14\%, não praticam.

Tabela 2. Empresas que praticam e desenvolvem atividades voltadas a sustentabilidade.

\begin{tabular}{lr} 
Questionamento & Percentual \\
\hline Sim & $75,86 \%$ \\
Não & $24,14 \%$ \\
\hline Fonte: Dados da pesquisa (2017).
\end{tabular}

Com relação as práticas realizadas pelas organizações, que visam a sustentabilidade, na Tabela 3 pode ser observado que 18,52\% dos entrevistados não conhece o conceito de 
sustentabilidade, $22,22 \%$ conhece o conceito de sustentabilidade e não prática e 59,26\%, conhece o conceito de sustentabilidade e pratica. Com isso, percebe-se que a sustentabilidade já se tornou um assunto de conhecimento da maioria das pessoas entrevistadas e que grande parte delas já praticam de alguma forma a sustentabilidade, em seu ambiente de trabalho. Por sua vez, Kneipp et al. (2012) em seu estudo, apontou evidências de empresas que afirmem práticas de gestão relacionadas ao comportamento ético, estão relacionados com a busca de certificações e foram constatadas poucas ações. Quanto a gestão ambiental, as empresas estão preocupadas em atender os requisitos legais e as exigências mercadológicas. Porém, na área de gestão social, mostrou que está bastante presente nas empresas analisadas, mas principalmente no que se refere aos funcionários e a comunidade local. Entretanto, Gollo et al. (2013) em empresas analisadas em seu estudo, mostrou que, com relação a sustentabilidade social, as empresas investem mais em capacitação e desenvolvimento de pessoas e pouca interação com a comunidade local.

Tabela 3. Práticas realizadas pelas organizações que visam a sustentabilidade.

\begin{tabular}{c|c|c}
\hline \multicolumn{1}{c|}{ Questionamento } & Categoria & Ocorrência \\
\hline $\begin{array}{c}\text { Quais são as práticas } \\
\text { realizadas pela organização } \\
\text { que visam à sustentabilidade? }\end{array}$ & $\begin{array}{c}\text { Conhece o conceito de sustentabilidade e } \\
\text { prática }\end{array}$ & $59,26 \%$ \\
& $\begin{array}{c}\text { Conhece o conceito de sustentabilidade e } \\
\text { não prática }\end{array}$ & $22,22 \%$ \\
& Não conhece o conceito de sustentabilidade & $18,52 \%$ \\
\hline
\end{tabular}

Fonte: Dados coletados pesquisa (2017).

Na Tabela 4, observa-se os entrevistados que acreditam que, quando uma empresa considera os pilares da sustentabilidade na sua gestão, ela adquire também, vantagem competitiva, a maioria dos entrevistados acreditam que sim, com $86,2 \%$ e o que não acreditam representam $13,8 \%$.

Tabela 4. Demonstrativo dos entrevistados que acreditam ou não que a sustentabilidade gera competitividade.

\begin{tabular}{lr} 
Questionamento & Percentual \\
\hline Sim & $86,2 \%$ \\
Não & $13,8 \%$ \\
\hline
\end{tabular}

Fonte: Dados coletados pesquisa (2017). 
Como pode ser visto na Tabela 5, empresas que consideram os pilares da sustentabilidade na sua gestão, pode-se adquirir maior vantagem competitiva. Os dados mostram que $90 \%$ acreditam que quando uma empresa adere a sustentabilidade, consequentemente adquire vantagem competitiva e 10\%, não acredita que sustentabilidade é fonte de competitividade. Segundo Silva et al. (2014), a maior parte das organizações relaciona a sustentabilidade, a permanência da própria organização. Entretanto, Vital et al. (2009) demonstra em sua pesquisa que os consumidores estão mais adeptos a produtos que sejam menos agressivos ao meio ambiente ou a produtores que tenham maior apelo a causa ambiental.

Tabela 5. Analise das empresas com relação a sustentabilidade e a competitividade.

\begin{tabular}{c|c|c}
\hline QUESTIONAMENTO & CATEGORIA & OCORRÊNCIA \\
\hline $\begin{array}{c}\text { Você acredita que } \\
\text { quando uma empresa } \\
\text { considera os pilares da } \\
\text { sustentabilidade na sua } \\
\text { gestão, ela adquire } \\
\text { também, vantagem } \\
\text { competitiva? }\end{array}$ & $\begin{array}{c}\text { Acredita que quando uma } \\
\text { empresa adere a } \\
\text { sustentabilidade, ela adquire } \\
\text { vantagem competitiva }\end{array}$ & $90 \%$ \\
\hline
\end{tabular}

Fonte: Dados da pesquisa (2017).

No decorrer da análise dos dados surgiu a hesitação com relação ao conhecimento dos entrevistados sobre sustentabilidade, se haveria alguma correlação com o grau de escolaridade ou se poderiam estar tendo conhecimento através de outros meios de informação. A partir desta indagação submeteu-se a questão ao teste do qui-quadrado para verificar se o conceito de sustentabilidade independe do grau de escolaridade dos gestores, sendo que o teste do quiquadrado não demonstrou dependência estatisticamente significativa $(p=0,4759)$ entre o conhecimento do conceito de sustentabilidade dos gestores está relacionado ao grau de escolaridade. Como pode ser visto na Tabela 6. 
Tabela 6: Valores relacionados ao conhecimento do conceito de sustentabilidade e o grau de escolaridade.

\section{Qui-Quadrado $<$ p $>$ calculado $<$ p $>$ esperado}

$\begin{array}{lccc}\text { Partição 1 } & 0.9941 & 0.3187 & \\ \text { Partição 2 } & 0.4909 & 0.4835 & * 0,05 \\ \text { Geral } & 1.4850 & 0.4759 & \\ & & \\ \mathrm{X}^{2}=\text { P } \leq 0,05 & \text { (Nível de significância) - Teste qui-quadrado de } \\ \text { independência: partição x c; form. x infor. x categorias. }\end{array}$

Considerando o valor $\langle\mathrm{p}\rangle$, todos os resultados mostram que $\langle\mathrm{p}\rangle$ é maior que 0,05 , mostrando resultado estatisticamente não significativo. Essa análise permite identificar que não se rejeita a hipótese nula, ou seja, estatisticamente todas as médias são iguais e não existe dependência entre as variáveis estudadas.

Contudo, através da análise dos questionários, entende-se que as empresas têm adquirido consciência de sua responsabilidade social, ambiental e econômica. Acreditando-se que a sustentabilidade gera competitividade para as organizações.

Entre os dezessete objetivos da ONU com relação a sustentabilidade, está incluso "Assegurar padrões de produção e de consumo sustentáveis", a partir do momento que as empresas trabalham de forma sustentável, tanto na produção de seus produtos quanto com os seus colaboradores está mudando a cultura de consumo entre as pessoas e das organizações, as quais são agentes influenciadores, dentro da sociedade.

\section{Considerações finais}

A busca das organizações por se adaptarem a práticas ambientais e sociais, além dos benefícios adquiridos por exercerem estas atividades, elas estão também se adequando as mudanças do mercado de consumo à medida que se renovam e se reinventam.

A aceleração tecnológica, a globalização, o aumento das expectativas dos consumidores, tem pressionado as organizações utilizarem todos os instrumentos de que puderem para se manterem nesse ambiente cada vez mais inovador e competitivo. 
O objetivo deste artigo foi explorar qual a visão dos gestores de empresas de pequeno e médio porte situadas no centro comercial de Juazeiro - BA, sobre sustentabilidade. A técnica de pesquisa utilizada foi o estudo de caso e a coleta de dados ocorreu por meio de entrevista instrumentalizada por um questionário estruturado. Para a análise, utilizou-se análise de conteúdo temática.

Em referência a questão-problema que norteou essa pesquisa, que foi: como se encontra a percepção conceitual dos gestores das empresas sobre sustentabilidade? Esses gestores acreditam que há relação entre sustentabilidade e competitividade? Pode-se inferir que, a grande maioria dos gestores, conhecem os conceitos que norteiam os pilares da sustentabilidade, eles dizem que praticam e desenvolvem atividades voltadas a sustentabilidade e acreditam que a sustentabilidade gera competitividade. Desse modo, pode-se dizer que as empresas têm tomado consciência, de que sustentabilidade pode gerar competitividade e a grande importância tanto para a sociedade quanto para o meio ambiente, de trabalhar de forma sustentável.

Ressalta-se, como limitação do estudo no decorrer das entrevistas a dificuldade de encontrar os gestores presentes nas organizações, e os dados coletados pelas informações que os participantes deram como auto-relato. Sugere-se que o Shopping direcione esforços para desenvolver práticas, no sentido de promover o conhecimento dos pilares da sustentabilidade, a todos os seus colaboradores, para que assim, aqueles que demonstraram alguma insegurança com relação ao assunto abordado, possam entender e implementar práticas sustentáveis dentro dos seus estabelecimentos.

Como perspectiva de pesquisa futura, sugere-se a elaboração de ferramentas que identifiquem o que os gestores apontam como praticar sustentabilidade social, ambiental e econômica.

\section{Referências}

BARDIN, L. Análise de conteúdo. Lisboa: Edições 70, 2004. 
BERTUCCI, Janete Lara de Oliveira. Metodologia básica para elaboração de trabalhos de conclusão de cursos (TCC): ênfase na elaboração de TCC de pós-graduação Lato Sensu. 1. ed.- 4. reimpr. - São Paulo: Atlas, 2012.

BRUNI, Adriano Leal. Estatística aplicada à gestão empresarial. 3. Ed. São Paulo: Atlas, 2011.

DIAS, Reinaldo. Gestão ambiental: responsabilidade social e sustentabilidade. 2. ed. São Paulo: Atlas, 2011.

FROEHLICH, Cristiane. Publicações internacionais sobre sustentabilidade: uma revisão de artigos com o uso da técnica de análise de conteúdo qualitativa. Revista de administração, UFSM. Santa Maria, 2014. Disponível em:

$\leq$ https://periodicos.ufsm.br/reaufsm/article/view/6519 HYPERLINK

"https://periodicos.ufsm.br/reaufsm/article/view/6519" $\geq$. Acesso em: 28 jul. 2017.

GOLLO, L. B. et al. Análise da sustentabilidade socioambiental de uma empresa do ramo têxtil da cidade de Erechim\RS. Revista de administração IMED. Passo Fundo, 2013. v. 3, n. 1, p. 19-32, 2013. Disponível em: https://seer.imed.edu.br/index.php/raimed/article/view/320 HYPERLINK "https://seer.imed.edu.br/index.php/raimed/article/view/320"> . Acesso em: 17 maio 2017.

KNEIPP, M. J. et al. Gestão para a sustentabilidade em empresas do setor mineral. Revista gestão. Org. Santa Catarina, v.14, n.33, p. 52, ago. 2012. Disponível em:

<https://periodicos.ufsc.br/index.php/adm/article/view/23825>. Acesso em: 15 jul. 2017.

LAVORATO, Marilena Lino de Almeida. BenchMais 3: As 311 melhores práticas em gestão socioambiental do Brasil. São Paulo: Biografia, 2015.

MARCONI, M.A.; LAKATOS, E.M. Fundamentos de Metodologia Científica. 7. ed. São Paulo: Atlas, 2007.

MEDICI, André Cezar. BenchMais 3: as 311 melhores práticas em gestão socioambiental do Brasil. São Paulo: Biografia, 2015. Cap. 2, p. 26.

ONUBR, Nações Unidas no Brasil. Agenda 2030 para o desenvolvimento sustentável: Conheça os dezessete Objetivos de Desenvolvimento sustentável da ONU. Disponível em: 〈http://nacoesunidas.org/tema/agenda2030 >. Acesso em: 02 dez. 2017.

REIS, Nelson Pereira. BenchMais 3: as 311 melhores práticas em gestão socioambiental do Brasil. São Paulo: Biografia, 2015. Cap. 2, p. 112.

SILVIA, S. S.; REIS, R. P.; AMÂNCIO, R. Conceitos atribuídos à sustentabilidade em organizações de diferentes setores. Revista de ciências da administração. Santa Catarina, v.16, n. 40, p. 90-103, dez. 2014. Disponível em:

<https://periodicos.ufsc.br/index.php/adm/article/view/2175-8077>. Acesso em: 20 jun. 2017. 
VITAL, T. J. et al. A influência da participação no índice de sustentabilidade empresarial (ISE) no desempenho das empresas. Revista de ciências da administração. Santa Catarina, v.11, n.24, p. 11-40, maiolago. 2009. Disponível em:

<https://periodicos.ufsc.br/index.php/adm/article/view/12181>. Acesso em: 05 set. 2017.

\section{Como citar este artigo (Formato ABNT):}

NOVAIS, Aritana Paola Santos Carvalho; SILVA, Adriano Victor Lopes da; OLIVEIRA, Erika Maria Jamir de. Percepção Conceitual Sobre Sustentabilidade: um Levantamento com Gestores de um Shopping. Id on Line Rev.Mult. Psic., 2018, vol.12, n.42, p. 584-601. ISSN: 1981-1179.

Recebido: 04/10/2018;

Aceito: 09/10/2018 